\title{
Preparation and characterization of $\mathrm{Bi}_{2} \mathrm{~S}_{3}$ compound semiconductor
}

\author{
M P DESHPANDE ${ }^{1}$, PALLAVI N SAKARIYA ${ }^{1,2, *}$, SANDIP V BHATT ${ }^{1}$, NIKITA H PATEL ${ }^{1}$, \\ KAMAKSHI PATEL ${ }^{1}$ and $S$ H CHAKI ${ }^{1}$ \\ ${ }^{1}$ Department of Physics, Sardar Patel University, Vallabh Vidyanagar 388 120, Gujarat, India \\ ${ }^{2}$ Babaria Institute of Technology, NH-8, Varnama, Vadodara 391 240, Gujarat, India
}

MS received 12 February 2014; revised 17 April 2014

\begin{abstract}
Bi}_{2} \mathrm{~S}_{3}$ single crystals were grown by the chemical vapour transport technique using ammonium chloride $\left(\mathrm{NH}_{4} \mathrm{Cl}\right)$ as a transporting agent. The stoichiometry of $\mathrm{Bi}_{2} \mathrm{~S}_{3}$ single crystal was confirmed by energy-dispersive analysis of X-rays (EDAX). The powder X-ray diffraction (XRD) pattern showed that $\mathrm{Bi}_{2} \mathrm{~S}_{3}$ crystals belong to the orthorhombic phase with calculated lattice constant $a=11.14 \AA, b=11.30 \AA$ and $c=3.96 \AA$. Scanning electron microscopy (SEM) pictures indicate the presence of layer lines on the surface of crystals thereby proving that these crystals are grown by layer by layer mechanism. We studied the transport properties viz. Hall effect, resistivity, thermoelectric power and thermal conductivity on $\mathrm{Bi}_{2} \mathrm{~S}_{3}$ pellets. Raman spectroscopy and thermal gravimetric analysis (TGA) were carried out on $\mathrm{Bi}_{2} \mathrm{~S}_{3}$ single crystal for studying their optical and thermal behaviours.
\end{abstract}

Keywords. Single crystal; chemical vapour transport technique; semiconductor.

\section{Introduction}

Over the past few decades, semiconducting chalcogenides compounds $\left(A_{2} B_{3}\right.$ with $A=\mathrm{Sb}, \mathrm{Bi}$, As and $\left.B=\mathrm{S}, \mathrm{Se}, \mathrm{Te}\right)$ have been receiving much attention because of their wide range of applications in various field of science and technology. One of the most promising areas is their use in thermoelectric refrigeration. The $\mathrm{V}_{2}-\mathrm{VI}_{3}$ binary compounds such as $\mathrm{Bi}_{2} \mathrm{~S}_{3}, \mathrm{Bi}_{2} \mathrm{Te}_{3}, \mathrm{Bi}_{2} \mathrm{Se}_{3}$ are narrow band gap semiconductors with homologous layered crystal structure and are interesting and important because of their major contribution in solar cells, photodetectors, opto-electronic, light amplifiers, electro-photography, light-emitting diodes, lasers, photoelectrochemical cells. ${ }^{1} \mathrm{Bi}_{2} \mathrm{~S}_{3}$ semiconductor with the direct band gap $\Delta E_{\mathrm{g}}=1.3 \mathrm{eV}^{2,3}$ has been suggested to be useful material for photodiode arrays or photovoltaic applications. ${ }^{4-6}$

\section{Experimental}

\subsection{Experimental procedure}

Single crystals of $\mathrm{Bi}_{2} \mathrm{~S}_{3}$ were prepared from high purity $(99.999 \%)$ bismuth (Bi) and sulfur (S) powders. Firstly, the powders were weighed and loaded into thoroughly cleaned thick walled quartz ampoule. The ampoule was then evacuated to $10^{-5}$ torr and sealed and then placed in the horizontal single zone furnace to prepare charge at $630^{\circ} \mathrm{C}$ for 3 days. The prepared charge was taken in another quartz ampoule with $\mathrm{NH}_{4} \mathrm{Cl}$ as a transporting agent and then again sealed at $10^{-5}$ torr and placed in the dual zone furnace at temperature $650^{\circ} \mathrm{C}$ of the source zone and growth zone at $600^{\circ} \mathrm{C}$. After

\footnotetext{
* Author for correspondence (pallavisakria11@gmail.com)
}

8 days, the furnace was cooled to room temperature and then ampoule was taken out from the furnace and broken which resulted in the growth of single crystals of $\mathrm{Bi}_{2} \mathrm{~S}_{3}$ in shape of needles. The length of these grown $\mathrm{Bi}_{2} \mathrm{~S}_{3}$ single crystals varied between 0.1 and $0.3 \mathrm{~cm}$ as shown in figure 1 .

\subsection{Characterization techniques}

Grown single crystals of $\mathrm{Bi}_{2} \mathrm{~S}_{3}$ were characterized by energydispersive analysis of X-rays (EDAX) (Philips EM 400 electron microscope) for elemental identification and by powder X-ray diffraction (XRD) (Philips Xpert MPD) for structure determination. The surface morphology was studied by using scanning electron microscopy (SEM) (Model-XL 30 ESEM). The electrical resistivity and thermoelectric power were measured over the temperature range $40-150^{\circ} \mathrm{C}$ whereas thermal conductivity was measured at $100^{\circ} \mathrm{C}$. The Hall effect experiment was carried out at room temperature. Raman scattering experiments were carried out at room temperature under the backscattering geometry using a Jobin-Yvon Horiba labram, HR800 single monochromator coupled with 'peltier cooled' charged coupled device (CCD) with 488 nm line Argon $\left(\mathrm{Ar}^{+}\right)$laser source. We also studied thermogravimetric analysis (TGA) on the sample in the range between room temperature and $700^{\circ} \mathrm{C}$ in $\mathrm{N}_{2}$ atmosphere to know the thermal stability of the material.

\section{Results and discussion}

\subsection{Elemental and structural characterization}

The composition of grown crystals were determined by the spectra obtained from the EDAX which is shown in figure 2. 


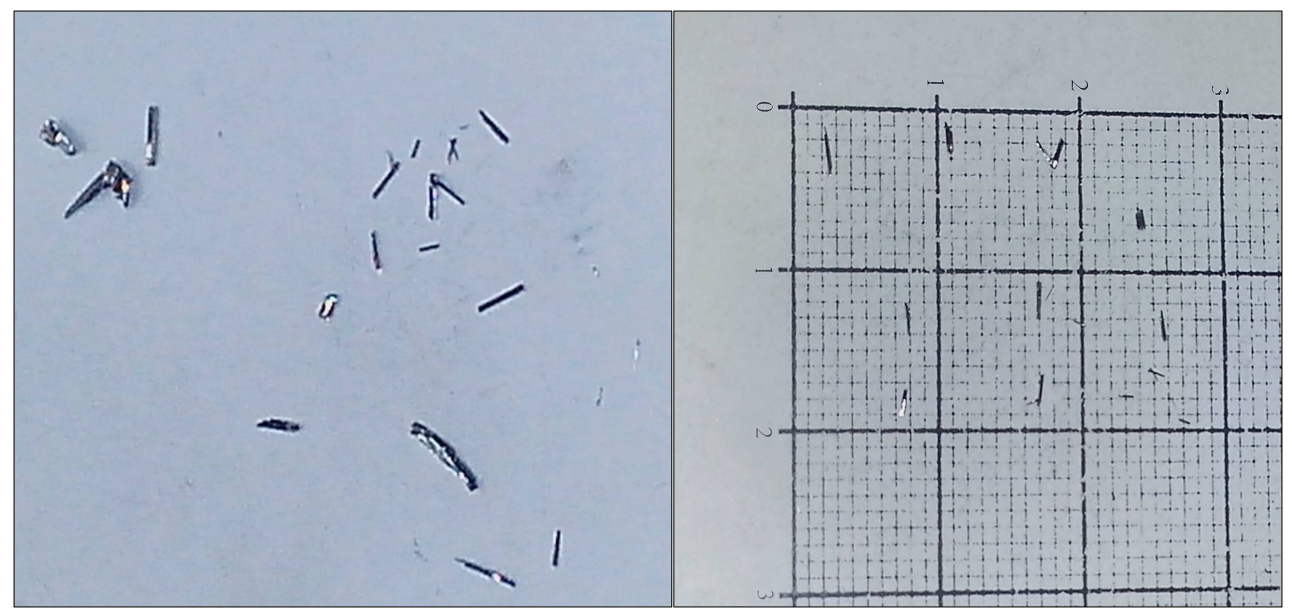

Figure 1. Photograph of $\mathrm{Bi}_{2} \mathrm{~S}_{3}$ single crystals grown in different sizes.

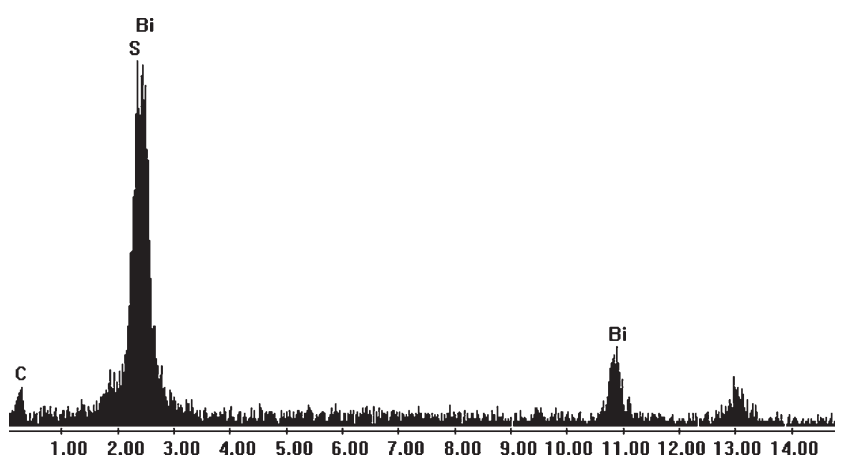

Figure 2. EDAX of $\mathrm{Bi}_{2} \mathrm{~S}_{3}$ single crystals.

The weight percentage observed from EDAX spectra of each element in sample is given in table 1. This table reveals that the grown crystals are rich in bismuth content in comparison to sulfur. Whereas small impurities of carbon (C) is seen because of carbon replica used in this analysis.

The XRD pattern of the $\mathrm{Bi}_{2} \mathrm{~S}_{3}$ crystalline powder is shown in figure 3. From this figure it is found that almost all diffraction peaks in the pattern could be indexed based on orthorhombic phase of $\mathrm{Bi}_{2} \mathrm{~S}_{3}$ (JCPDS no. 17-0320) with lattice constant $a=11.14 \AA$, $b=11.30 \AA, c=3.96 \AA$. The calculated density, volume and cla ratio are given in table 2. We used Scherrer's formula ${ }^{7}$ to calculate the crystallite size for various reflections, which shows variation in size from 45 to $75 \AA$.

Figure 4 shows the photographs of the surface morphology of $\mathrm{Bi}_{2} \mathrm{~S}_{3}$ single crystal studied by scanning electron microscopy. It is seen that $\mathrm{Bi}_{2} \mathrm{~S}_{3}$ single crystal possesses a flat surface as shown in figure $4 \mathrm{a}$. The magnified images of as seen single-crystal surface shows some layer lines in figure $4 \mathrm{~d}-\mathrm{f}$ which is an indication that these crystals are grown by layer growth mechanism. Figure $4 \mathrm{e}$ and $\mathrm{f}$ is also
Table 1. Chemical composition (wt $\%$ ) of grown $\mathrm{Bi}_{2} \mathrm{~S}_{3}$ single crystal.

\begin{tabular}{lcc}
\hline Element & Obtained wt $\%$ & Calculated wt $\%$ \\
\hline $\mathrm{Bi}$ & 68.26 & 81.29 \\
$\mathrm{~S}$ & 10.14 & 18.71 \\
$\mathrm{C}$ & 21.61 & - \\
\hline
\end{tabular}

reflecting that how one layer is displayed with respect to other layer.

\subsection{Transport properties}

The electrical resistivity of $\mathrm{Bi}_{2} \mathrm{~S}_{3}$ pellets was studied in the temperature range 306-403 K using dc four-probe method. Figure 5 shows the Arrhenius plot of change in resistivity $(\rho)$ as a function of reciprocal of temperature. It is seen that resistivity decreases with increase in temperature, indicating semiconducting nature of $\mathrm{Bi}_{2} \mathrm{~S}_{3}$ compound. The thermal activation energy is calculated using relation ${ }^{8}$ which comes out to be $0.38 \mathrm{eV}$.

Figure 6 shows the variation of Seebeck co-efficient $(S)$ as a function of reciprocal of temperature for $\mathrm{Bi}_{2} \mathrm{~S}_{3}$ pellets. It is reflected that as temperature increases thermoelectric power ' $S$ ' decreases. The values of Seebeck coefficient ' $S$ ' is negative suggesting that sample is behaving $n$-type in nature which may be because of excess of bismuth in sample. From the plot of $S$ vs. 1/T shown in figure 6 we calculated the Fermi energy $\left(E_{\mathrm{F}}\right)$, constant $A$ and scattering parameter(s) in two regions which are given in table 3 using well-known expression ${ }^{9}$ given as

$$
S= \pm \frac{k}{e}\left[A+\frac{E_{\mathrm{F}}}{k T}\right]
$$




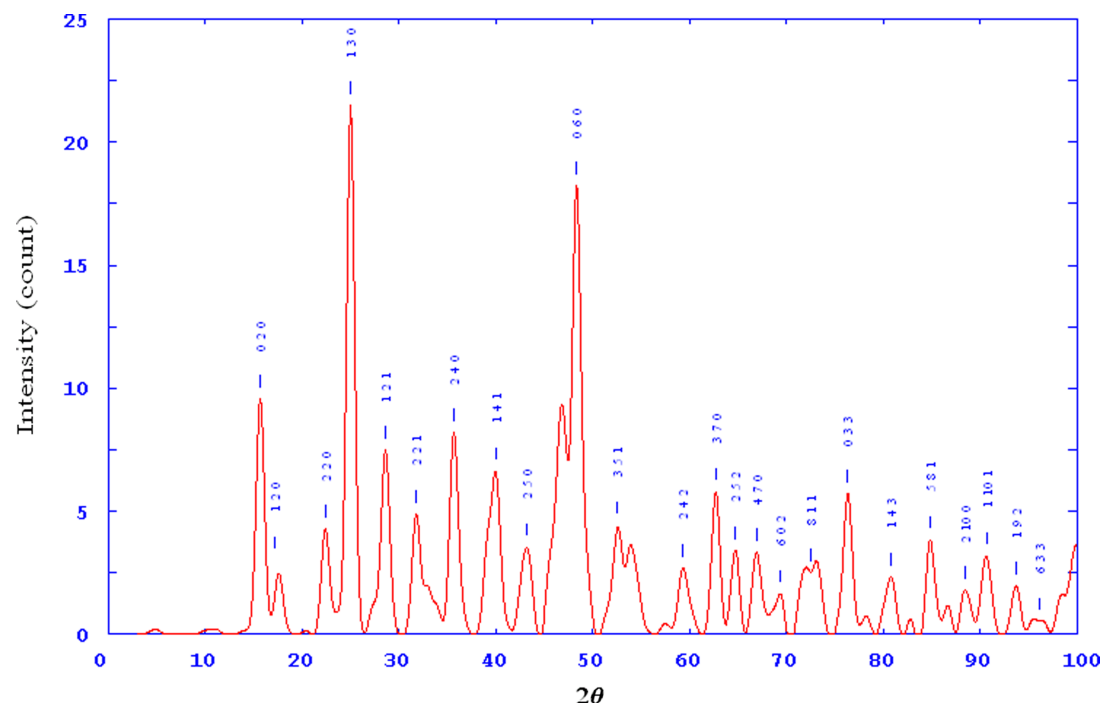

Figure 3. XRD pattern of $\mathrm{Bi}_{2} \mathrm{~S}_{3}$ crystalline powder.

Table 2. Lattice parameter, $c / a$ ratio, unit cell volume and density obtained from X-ray diffractrogram for $\mathrm{Bi}_{2} \mathrm{~S}_{3}$ compound.

\begin{tabular}{lc}
\hline & \multicolumn{1}{c}{$\mathrm{Bi}_{2} \mathrm{~S}_{3}$} \\
\cline { 2 - 2 } Lattice parameter & Calculated value \\
\hline$a(\AA)$ & 11.14 \\
$b(\AA)$ & 11.30 \\
$c(\AA)$ & 3.96 \\
Volume $(\AA)^{3}$ & 498.49 \\
Density $\left(\mathrm{g} \mathrm{cm}^{-3}\right)$ & 6.84 \\
\hline
\end{tabular}

where $k$ is the Boltzmann constant, $e$ the electronic charge, $A$ the dimensionless parameter determined by the dominant scattering process and $E_{\mathrm{F}}$ the separation of the Fermi level from the top of the valence band. These parameters along with their values obtained is displayed in table 3 . The value of scattering parameter(s) 2.31 and 2.29 in two different temperature regions clearly suggest that lattice vibrations is dominant scattering mechanism in this sample.

Thermal conductivity of the $\mathrm{Bi}_{2} \mathrm{~S}_{3}$ single crystalline pellet was determined at $100^{\circ} \mathrm{C}$ and it comes out to be $0.422 \mathrm{~W} \mathrm{~cm}^{-1} \mathrm{deg}^{-1}$. To be a useful thermoelectric material, it must have large thermoelectric figure of merit defined as $Z=S^{2} / K \rho$, or its dimensionless equivalent $Z T$. But in our result calculated figure of merit $Z T$ of $\mathrm{Bi}_{2} \mathrm{~S}_{3}$ crystalline pellets comes out to be very low which suggests that prepared pellets of $\mathrm{Bi}_{2} \mathrm{~S}_{3}$ crystals grown by the chemical vapour transport technique may not be suitable for thermoelectric application in comparison to those grown by the Bridgman technique. ${ }^{10}$

From the measurement of Hall effect at room temperature, it is evident that the sign of Hall coefficient of $\mathrm{Bi}_{2} \mathrm{~S}_{3}$ is negative. This indicates that the compound is $n$-type semiconductor matching with the results of Seebeck coefficient.
The values of calculated Hall coefficient, Hall mobility and carrier concentration at room temperature are shown in table 4.

\subsection{Optical and thermal analysis}

Raman spectroscopy was conducted at room temperature using Raman spectrometer and $\mathrm{Ar}^{+}$laser $(488 \mathrm{~nm}$ ) has been used to excite the sample. $\mathrm{Bi}_{2} \mathrm{~S}_{3}$ belongs to the orthorhombic space group pbnm with 20 atoms per primitive cell. For a 20-atom $\mathrm{Bi}_{2} \mathrm{~S}_{3}$ primitive cell, there are 60 zonecenter phonon modes that can be classified according to the $D_{2 \mathrm{~h}}$ point-group symmetry: $10 A_{\mathrm{g}}+10 B_{1 \mathrm{~g}}+5 B_{2 \mathrm{~g}}+5 B_{3 \mathrm{~g}}+$ $5 A_{\mathrm{u}}+5 B_{1 \mathrm{u}}+10 B_{2 \mathrm{u}}+10 B_{3 \mathrm{u}}$. Out of these, only $A_{\mathrm{g}}, B_{1 \mathrm{~g}}$, $B_{2 \mathrm{~g}}$, and $B_{3 \mathrm{~g}}$ modes are Raman active. ${ }^{11}$

Raman spectrum of $\mathrm{Bi}_{2} \mathrm{~S}_{3}$ single crystal shown in figure 7 shows three Raman active optical phonon peaks at 186,238 and $264 \mathrm{~cm}^{-1}$, which are matched with the reported values. ${ }^{12,13}$ Here peaks at 186 and $238 \mathrm{~cm}^{-1}$ are corresponding to $A_{\mathrm{g}}$ phonon mode while peak at $264 \mathrm{~cm}^{-1}$ corresponds to $B_{1 \mathrm{~g}}$ phonon mode. ${ }^{11}$

The thermogravimetric analysis (TGA) curve of $\mathrm{Bi}_{2} \mathrm{~S}_{3}$ single crystal from room temperature to $700^{\circ} \mathrm{C}$ under $\mathrm{N}_{2}$ is shown in figure 8 . It is observed from the TGA analysis that sample possess stability up to $\sim 500^{\circ} \mathrm{C}$ and then a very smooth decomposition occurs approximately from 500 to $700^{\circ} \mathrm{C}$ with weight loss of $10 \%$. This weight loss can be attributed to the loss of sulfur in the form of $\mathrm{SO}_{2}$ and the remaining product finally turns into residue $\mathrm{Bi}_{2} \mathrm{O}_{3}$. This observation can be confirmed form DTA/DTG analysis that can give endothermic peak at this temperature which is corresponding to weight loss of $\mathrm{SO}_{2} \cdot{ }^{14}$ We have used Broido (BR) relation ${ }^{15}$ for calculating the activation energy in the weight loss region which is shown in figure 9. Calculated activation energy from Broido relation is given in table 5 . 


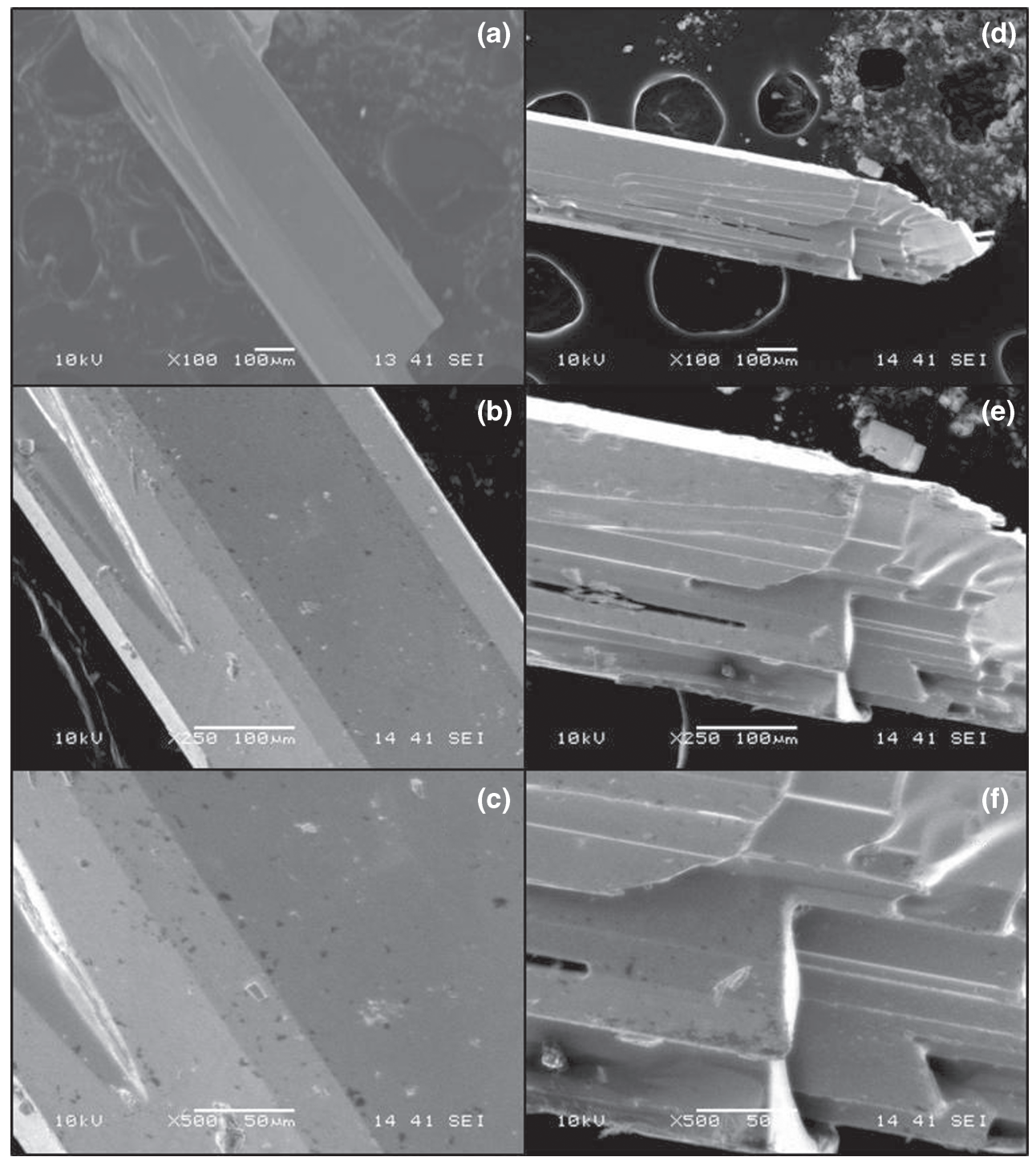

Figure 4. SEM images of $\mathrm{Bi}_{2} \mathrm{~S}_{3}$ single crystal.

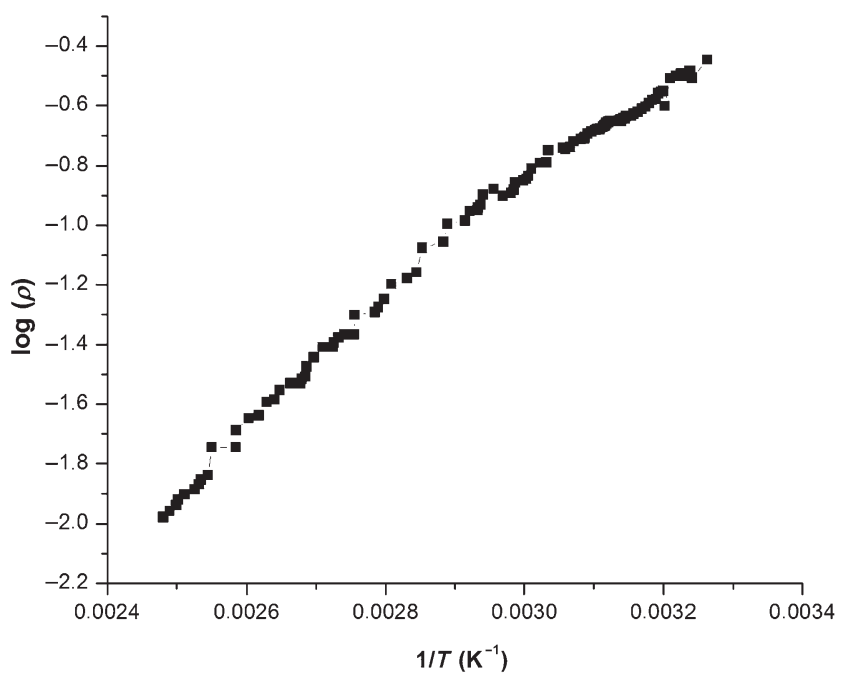

Figure 5. Variation of resistivity as a function of reciprocal of temperature.

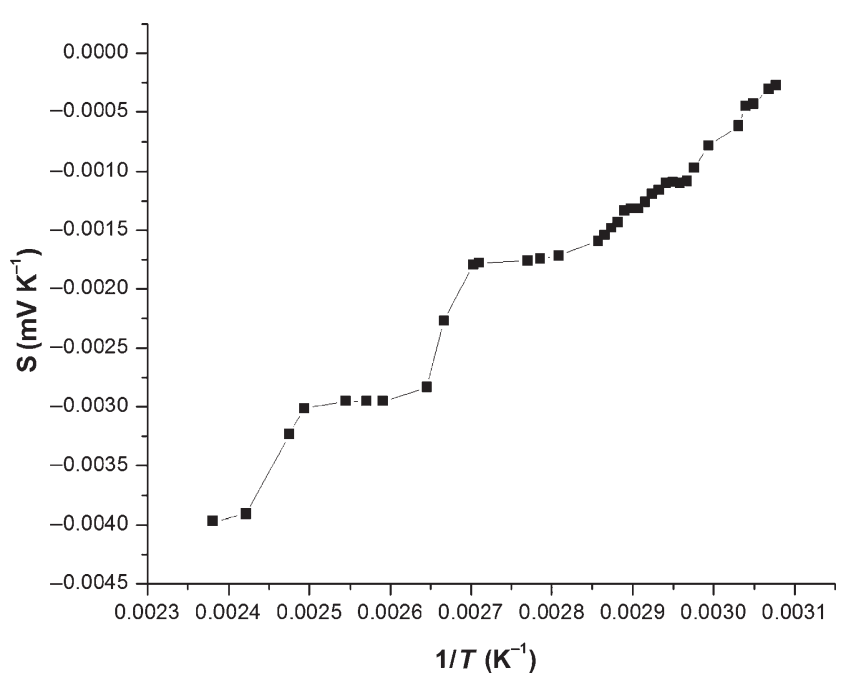

Figure 6. Plot of thermoelectric power $(S)$ as a function of reciprocal of temperature. 
Table 3. Values of constant $(A)$, scattering parameter $(S)$ and Fermi energy $\left(E_{\mathrm{F}}\right)$ of prepared $\mathrm{Bi}_{2} \mathrm{~S}_{3}$ pellets.

\begin{tabular}{lccc}
\hline $\begin{array}{l}\text { Temperature region } \\
(1 / T) \mathrm{K}^{-1} \times 10^{-4}\end{array}$ & $A$ & $S=(5 / 2-A)$ & $E_{\mathrm{F}}(\mathrm{meV})$ \\
\hline $31-27$ & 0.18 & 2.31 & 4.94 \\
$27-24$ & 0.21 & 2.29 & 5.75 \\
\hline
\end{tabular}

Table 4. Values of Hall coefficient, Hall mobility and carrier concentration.

\begin{tabular}{lc}
\hline Temperature & $\begin{array}{c}\text { Room temperature } \\
(303 \mathrm{~K})\end{array}$ \\
\hline Hall coefficient $\left(R_{\mathrm{H}}\right)$ & $-0.375 \mathrm{~cm}^{3} \mathrm{C}^{-1}$ \\
Hall mobility $(\mu)$ & $0.473 \mathrm{~cm}^{2} \mathrm{~V}^{-1} \mathrm{~s}^{-1}$ \\
Carrier concentration $(n)$ & $1.66 \times 10^{19} \mathrm{~cm}^{-3}$ \\
\hline
\end{tabular}

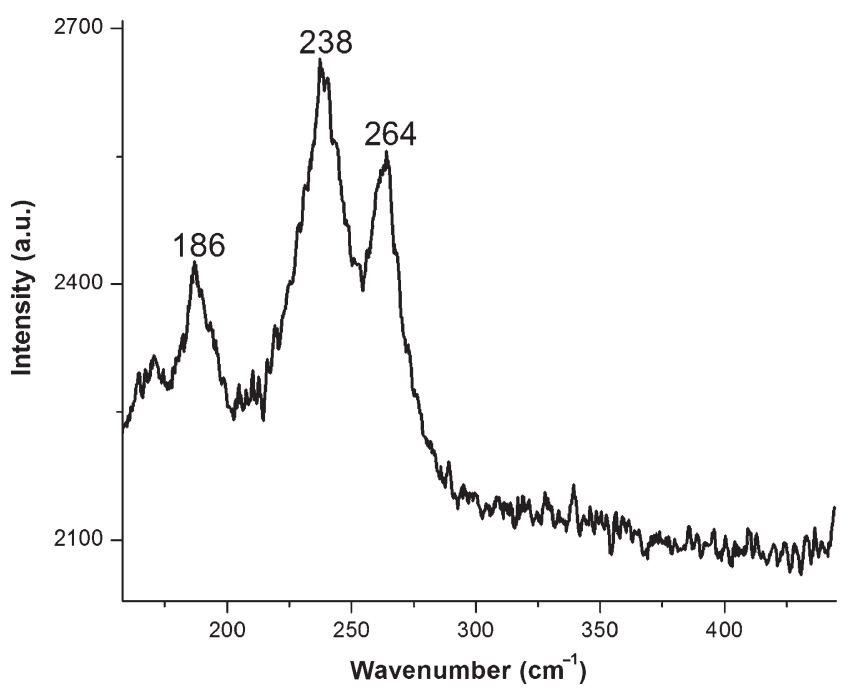

Figure 7. Raman spectrum of $\mathrm{Bi}_{2} \mathrm{~S}_{3}$ single crystal.

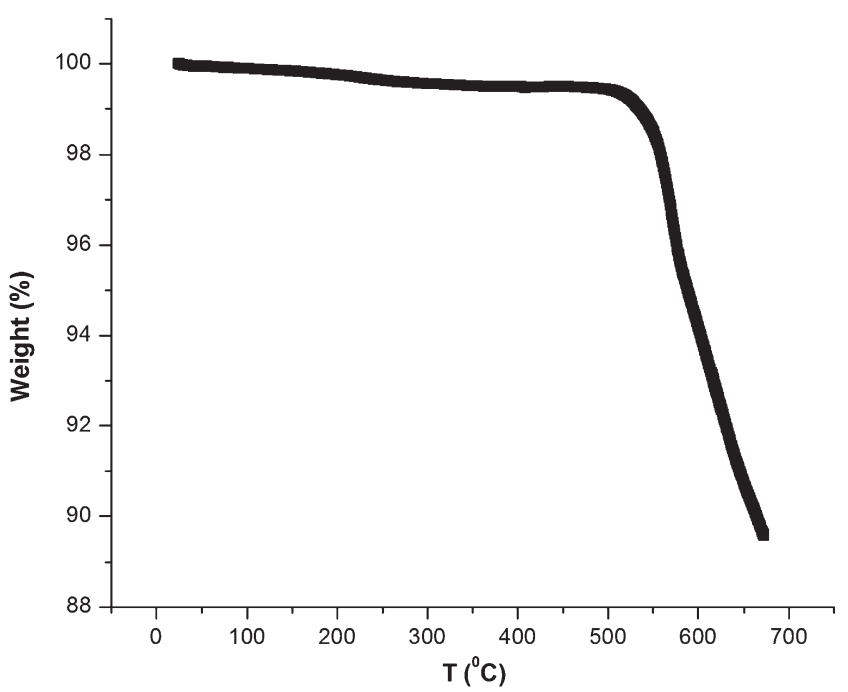

Figure 8. TGA of $\mathrm{Bi}_{2} \mathrm{~S}_{3}$ single crystal powder under $\mathrm{N}_{2}$.

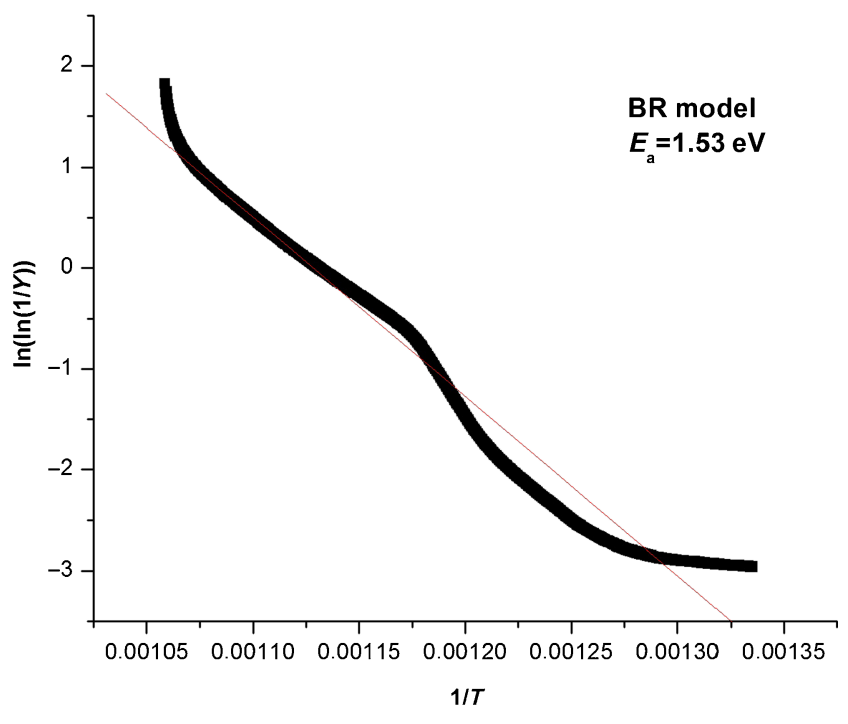

Figure 9. Plot of BR model of TGA in a weight loss region.

Table 5. Value of activation energy $(\mathrm{eV})$ for Broido model.

\begin{tabular}{lc}
\hline Name of model & Broido relation \\
\hline Activation energy & $1.53 \mathrm{eV}$ \\
\hline
\end{tabular}

\section{Conclusion}

Single crystals of $\mathrm{Bi}_{2} \mathrm{~S}_{3}$ were successfully grown in our laboratory by the chemical vapour transport technique. EDAX confirmed that $\mathrm{Bi}_{2} \mathrm{~S}_{3}$ crystals are rich in $\mathrm{Bi}$ content in comparison to $S$ and powder XRD pattern indicated that $\mathrm{Bi}_{2} \mathrm{~S}_{3}$ crystallizes in a pure orthorhombic structure with calculated lattice parameters $a=11.14 \AA, b=11.30 \AA, c=3.96 \AA$ which are matching with the reported JCPDF file. SEM images have shown that single crystals are grown by layer by layer mechanism. The semiconducting behaviour of $\mathrm{Bi}_{2} \mathrm{~S}_{3}$ single crystals is confirmed by resistivity, Seebeck and Hall coefficient measurements. Apart from this Seebeck and Hall measurements shows that grown $\mathrm{Bi}_{2} \mathrm{~S}_{3}$ single crystals are $n$-type in nature.

\section{Acknowledgements}

We are thankful to UGC, New Delhi, for sanctioning DRS/SAP (IIIrd phase) to the department and the individual UGC project which has made possible to carry out this work. We are also thankful to Dr. Vasant Sathe, IUC-DAE Indore, for providing facility for Raman spectroscopy.

\section{References}

1. Manea R K, Ajalkar B D and Bhosale P N 2004 Mater. Chem. Phys. 84247

2. Lokhande C D, Sankapai B R, Mane R S, Pathan H M, Muller M, Giersig M, Tributsch H and Ganeshan V 2002 Appl. Surf. Sci. 187108 
3. Nomoura R, Kanaya K and Matsuda H 1989 Bull. Chem. Soc. Jpn. 62939

4. Nayak B D, Acharya H N, Miitra G B and Mathur B K 1983 Thin Solid Films 10517

5. Pawar S H, Bhosale P N, Uplane M D and Tanhanker S 1983 Thin Soild Films 110165

6. Boudjouk P, Remington M P, Grier D G, Jarabek B R and Mc Carthy G J 1998 Inorg. Chem. 373538

7. Cullity B D 1978 Elements of X-rays diffraction (2nd ed) (Addison-Wesley) p. 102

8. Ubale A U, Daryapurkar A S, Mankar R B, Raui R R, Sangawar V S and Bhosale C H 2008 Mater. Chem. Phys. 110180
9. Perluzzo G, Lakhani A A and Jandl S 1980 Solid State Commun. 35301

10. Shaban H T, Nassary M M and El-Sadek M S 2008 J. Mater. Sci. Technol. 4031655

11. Zhao Y, Chua K T E, Gan C K, Zhang J, Peng B, Peng Z and Xiong Q H 2011 Phys. Rev. B 84205330

12. Han Q, Feng S, Sun Y, Wang X, Yang X and Lude L 2009 Mater. Lett. 631611

13. Shen X P, Yin G, Zhang W L and Xu Z 2006 Solid State Commun. 140116

14. Patel T K 2013 Adv. Appl. Sci. Res. 4115

15. Broido A 1969 J. Polym. Sci. 7A-2 1761 